\title{
CORRESPONDENCE
}

\section{OPHTHALMOLOGICAL COMPLICATIONS OF FAVISM}

\section{To the Editorial Committee of the British Journal of Ophthalmology}

Sirs,-I read with interest the article of Choremis, Joannides, and Kyriakides on "Severe Ophthalmological Complications following Favism" (Brit. J. Ophthal. (1960) 44, 353).

Since the authors state that "such complications were encountered for the first time and no information was found in the literature", I should like to refer your readers to a case published by my co-worker, Dr. G. Pasca, in 1945.

The patient, a farmer aged 55, from Sassari, Sardinia, after a meal of broad beans, entered a broad-bean field and suddenly developed general malaise with weakness and dizziness. During the night his temperature rose and he passed blood-stained urine. Jaundice also developed, and marked anaemia $(1,750,000$ erythrocytes) was found.

Three days later he was suddenly smitten with almost complete blindness. Fundus examination showed constricted arteries, slight enlargement of the veins, and a few haemorrhages scattered on the retina. The optic disc and adjacent portion of the retina were highly oedematous. The ocular tension was low: right eye $9 \mathrm{~mm} . \mathrm{Hg}$; left eye 8 $\mathrm{mm}$. Hg (Schiötz). Three weeks later complete optic atrophy was evident, and the visual acuity was reduced to perception of light.

The explanation given for the ophthalmological complication was similar to that proposed for amaurosis following blood loss, possibly with the co-existence of toxic factors.

This case, which is closely similar to the second case of Choremis and others (1960), has perhaps escaped the notice of most ophthalmologists in other countries, through having been published so soon after the war.

Yours faithfully,

ClinICA OCULISTICA,
UNIVERSITÀ DI ROMA,
ITALY.
July $16,1960$.

G. B. BIETTI.

July 16,1960

\section{REFERENCES}

Choremis, C., Joannides, T., and Kyriakides, B. (1960). Brit. J. Ophthal., 44, 353. PASCA, G. (1945). Boll. oculist., 24, 215.

\section{NOTES}

\section{National Council to Combat Blindness}

The National Council to Combat Blindness, Inc., was founded in 1946 with the primary purpose of financing research in ophthalmology and related sciences. The objective of its programme is the ultimate reduction of blinding eye diseases and ocular disorders, through increased basic and clinical research in the field of scientific investigation.

The Council announces that completed applications for full-time research fellowships, grants-in-aid, and summer student fellowships for the 1961-62 period, must be sent in by March 1, 1961, and that the appropriate forms may be obtained from the Secretary, National Council to Combat Blindness, Inc., 41 West 57th Street, New York 19, N.Y. 